\title{
Developing a DEMATEL method to prioritize distribution centers in supply chain
}

\author{
Maghsud Amiri $^{a^{*}}$, Jamshid Salehi Sadaghiyani $^{\mathrm{a}}$, Nafiseh Payani ${ }^{\mathrm{b}}$, and Mahdi Shafieezadeh ${ }^{\mathrm{c}}$
}

${ }^{a}$ Department of Industrial Management, Allameh Tabatabaei University, Tehran, Iran

${ }^{b}$ Department of of Industrial Engineering, Science and Culture, Tehran, Iran

${ }^{c}$ Departemtn of Industrial Engineering, Yazd University, Yazd, Iran

AR T I L E I N F $\quad$ AB S T RAC T

Article history:

Received January 202010

Received in revised form

2 April 2011

Accepted 3 April 2011

Available online

6 April 2011

Keywords:

Supply chain management (SCM)

Distribution center (DC)

Balanced scorecard (BSC)

Decision making trial and

evaluation laboratory

(DEMATEL)
During the past two decades, there have been significant numbers of studies focusing on supply chain management for evaluating important factors on the success of a supply chain program. In this paper, we present a method to prioritize the locations of distribution centers in a supply chain. The proposed model of this paper uses balanced scorecard (BSC) to categorize the most important attributes affecting the location of distribution centers and the attributes are ranked based on decision making trial and evaluation laboratory (DEMATEL) method. The implementation of the proposed model of this paper is also applied for a real-world case study of oil company and the results are analyzed under different scenarios.

\section{Introduction}

Supply chain management (SCM) plays an important role on increasing productivity of any organization and there is an increasing interest on implementing efficient SCM techniques in the competitive environment (Zandin \& Maynard, 2001). Distribution centers (DC) are the point in supply chain where stocks are held, or buffered for varying periods of time (Schechter \& Sander, 2002). DCs are the warehouse facilities for holding inventory from manufacturing pending distribution to the appropriate stores and demand is one of most important factors influencing the location of any DC (Kanji \& Wong, 1999). BSC is a controlling instrument, which has received extensive treatment in literature (Karathanos \& Karathanos, 2005) and it has had the 'biggest impact on practice' over the past decade on strategic planning (Smith, 2005). Originally devised by Kaplan and Norton for a single private enterprise (Kaplan \& Norton, 1996, 2000), BSC has been adapted to networks of supply chains (e.g. Brewer and Speh, 2000).

There are cases in different fields such as engineering, economics and management where we face more than one single criterion for making an appropriate decision. In fact, there are many situations

* Corresponding author. Tel: +989121827322

E-mail addresses: mg_amiri@yahoo.com (M. Amiri) 
where we need to make a decision based on group's opinions. (George et al., 1992). During the past four decades, there have been different techniques to consider various criteria for ranking alternatives.

One of the group decision-making methods is decision-making trial and evaluation laboratory (DEMATEL) method, which uses matrices and diagrams for visualizing the structure of complicated causal relationships (Fontela \& Gabus, 1976). Hence, DEMATEL can separate the involved criteria of a system (or subsystem) into the cause and effect groups to ease the process of decision-making (Wu \& Lee, 2007). DEMATEL method has been successfully applied in different projects (Wu, 2008; Tzeng et al., 2007; Tsai and Chou, 2008). In this paper, we present an empirical method for group decision making for an oil industry project using an integrated BSC and DEMATEL techniques. The proposed model of this paper uses varieties of different criteria for decision-making strategies. The paper is organized as follows. The results of a literature review on related subjects are presented in the next section. In Section 2, the proposed methodology for using group decision making approach in building a structure for determining priorities of locating distribution centers in supply chain from strategic point of view and regarding to the balanced scorecard perspectives is depicted, and this is followed by an empirical study in Section 3. Section 4 concludes the paper with a discussion of the implications of this study, research directions, and concluding remarks.

\subsection{Literature review}

\subsubsection{Balanced scorecard}

Kaplan and Norton declare that strategy is a set of hypotheses about cause and effect. Making strategy work in organizations demands that we take advantage of all the competencies within the organization and articulate strategy with several perspectives in mind to ensure that balance is maintained (Kaplan \& Norton, 1993). Kaplan and Norton articulated four perspectives that can guide companies as they translate strategy into actionable terms.

Financial perspective: The revenues, margins, and expenses are very important for an organization seeking to achieve its goals. A common mistake in many organizations is that they forget the link between the financial goals and the non-financial strategy of the company. The financial perspective gives respect to the relationship between stated financial goals and other goals that feed the machine to create the result.

Customer perspective: The customer perspective is viewed as the set of objectives the organization must achieve to gain customer acquisition, acceptance, and perpetuation. Objectives are an outgrowth of assumptions made about the customers and their habits, the markets they represent, and the value they perceive in a relationship with the organization (Kaplan \& Norton, 2004).

Internal perspective: The internal perspective reminds us that the background works, driven by objectives and goals, must be in place to ensure that the customer and financial objectives are achieved. Internal processes, morals, cultures, and procedures in all departments and business units support the value proposition to the target market segments.

Learning and growth perspective: This perspective is the basis for all other perspectives and serves to remind the practitioner that the basis for all other results in the internal, customer, and financial perspectives are found in the learning and growth of the people. Learning dictated how people absorb new ideas and turn them into action (Nair, 2004).

\subsubsection{The influential criteria for selecting distribution centers' location}

An increasing number of contributions in the literature are dealing with the adaptation of BSC to fit the needs of SCM (Brewer \& Speh, 2000; Bullinger et al., 2002). BSC receives broad attention not only in scientific literature but also in practical applications. In addition to financial criteria, the BSC comprises a customer perspective, an innovation and learning perspective as well as an internal business perspective. These perspectives integrate a set of criteria into one management report that provides a deeper insight into a company's performance. The selected criteria depend on the 
individual situation faced by the company (Stadtler \& Kilger, 2005). Every criterion selected for BSC must be part of a link of cause-and-effect relationships, ending in financial objectives that represent a strategic theme for the business. The criteria are designed to pull people toward the overall vision. This methodology is consistent with the approach of supply chain management by helping managers overcome traditional functional barriers and ultimately leads to improved decision making and problem solving (Waters, 2007).

Selection of criteria for decision making about ranking location priorities is very important for distribution center location problem, so we review the works considered criteria in supply chain management. The criteria are categorized in four classes, based on BSC model; financial, customer, internal and learning and growth criteria summarized in Table 1.

\section{Table 1}

Four classes of criteria based on BSC model

\begin{tabular}{|c|c|c|}
\hline $\begin{array}{l}\text { BSC } \\
\text { Perspective }\end{array}$ & Influential Criteria & References \\
\hline \multirow{6}{*}{ Financial } & Increase stockholder value & Chorafas, 2001 \\
\hline & Profitability & Metters, 1997 \\
\hline & Investment cost & $\begin{array}{l}\text { Yong, 2006; Chu, 2002; Kuo et al., 2006; Chu \& Lai, 2005; Chou et al., } \\
2008\end{array}$ \\
\hline & Delivery Cost & Chan \& Lee, 2005 \\
\hline & Reduction of inventory & Ertugrul \& Karakasoglu, 2008; Yong, 2006; Chu, 2002; Kuo et al., 2006; \\
\hline & Investment in Chain ${ }^{*}$ & Chan \& Lee, 2005; Chu \& Lai, 2005; Delffmann, 2000 \\
\hline \multirow{6}{*}{ Customer } & Customer satisfaction & Delffmann, 2000 \\
\hline & Increase market share & Frazelle, 2002 \\
\hline & Proximity to customer & Kahraman et al., 2003; Chan \& Lee, 2005; Chu \& Lai, 2005 \\
\hline & Customer loyalty & Chorafas, 2001 \\
\hline & Reach new customer & Chorafas, 2001; Frazelle, 2002; Chan \& Lee, 2005 \\
\hline & Sales volume & Chan \& Lee, 2005 \\
\hline \multirow{4}{*}{ Internal } & Quality improvement & Delffmann, 2000 \\
\hline & New product development & $\begin{array}{l}\text { Yong, 2006; Chu, 2002; Kuo et al., 2006; Chu \& Lai, 2005; Chopra \& } \\
\text { Meindl, 2003; Smock, } 2003\end{array}$ \\
\hline & Equipment & Frazelle, 2002; Chou et al., 2008 \\
\hline & On time delivery & Frazelle, 2002 \\
\hline \multirow{6}{*}{$\begin{array}{l}\text { Learning \& } \\
\text { Growth }\end{array}$} & Innovation & Chan \& Lee, 2005 \\
\hline & Documentation & Frazelle, 2002 \\
\hline & Favorable Labor & Ertugrul \& Karakasoglu, 2008 \\
\hline & Skilled Worker & $\begin{array}{l}\text { Yong, 2006; Chu, 2002; Kuo et al., 2006; Chu \& Lai, 2005; Chou et al., } \\
2008\end{array}$ \\
\hline & Cultural view $^{* *}$ & Chorafas, 2001 \\
\hline & Logistics Information System & Frazelle, 2002 \\
\hline
\end{tabular}

"by proximity to Suppliers and Resources for availability of acquirement material

${ }^{* *}$ Efficiency, Coordination, Responsiveness and Competency

\section{Material and methods}

\subsection{The DEMATEL}

DEMATEL is a sophisticated method for establishing a structural model involving causal relationships among complex factors (Gabus \& Fontela, 1972, 1973). DEMATEL was developed by the science and human affairs program of the Battelle Memorial Institute of Geneva between 1972 and 1976 and it was used to solve the complicated and intertwined problem group. The methodology, according to the properties of objective affairs, can confirm the interdependence among the variables/attributes and restrict the relation that reflects the properties with an essential system and development trend. The end product of the DEMATEL process is a visual representation - an individual map of the mind - by which the respondent organizes his or her own action in the world 
(Hori \& Shimizu, 1999; Kamaike, 2001; Yamazaki et al., 1997; Yuzawa, 2002). The procedures of the DEMATEL method (Fontela \& Gabus, 1976) are discussed below.

Step 1: Generating the direct-relation matrix. We use four scales for measuring the relationship among different criteria: 0 (no influence), 1 (low influence), 2 (high influence), and 3 (very high influence). Next, decision makers prepare sets of the pair-wise comparisons in terms of effects and direction between criteria. Then the initial data can be obtained as the direct-relation matrix which is a $n \times n$ matrix $A$ where each element of $a_{i j}$ is denoted as the degree in which the criterion $i$ affects the criterion $j$.

Step 2: Normalizing the direct-relation matrix. Normalization is performed using the following,

$X=k \cdot A$

$k=\frac{1}{\max _{1 \leq i \leq n} \sum_{j=1}^{n} a_{i j}} \cdot i, j=1,2, \ldots, n$

Step 3: Attaining the total-relation matrix. Once the normalized direct-relation matrix $X$ is obtained, the total relation matrix $T$ can be acquired by using Eq. (3), where $I$ is denoted as the identity matrix

$T=X(1-X)^{-1}$

Step 4: Producing a causal diagram. The sum of rows and the sum of columns are separately denoted as vector $D$ and vector $R$ through Eqs. (4-6). Then, the horizontal axis vector $(D+R)$ named "Prominence" is made by adding $D$ to $R$, which reveals the relative importance of each criterion. Similarly, the vertical axis $(D-R)$ named "Relation"' is made by subtracting $D$ from $R$, which may divide criteria into a cause and effect groups. Generally, when $(D-R)$ is positive, the criterion belongs to the cause group and when the $(D-R)$ is negative, the criterion represents the effect group. Therefore, the causal diagram can be obtained by mapping the dataset of the $(D+R, D-R)$, providing some insight for making decisions.

$$
\begin{aligned}
T & =\left[t_{i j}\right]_{n \times n^{\prime}} \quad i, j=1,2, \ldots, n \\
D & =\left[\sum_{j=1}^{n} t_{i j}\right]_{n \times 1}=\left[t_{i .}\right]_{n \times 1} \\
R & =\left[\sum_{i=1}^{n} t_{i j}\right]_{1 \times n}=\left[t_{. j}\right]_{1 \times n}
\end{aligned}
$$

where vector $D$ and vector $R$, respectively denote the sum of rows and the sum of columns from totalrelation matrix $T=\left[t_{i j}\right]_{n \times n}$.

Step 5: Obtaining the inner dependence matrix. In this step, the sum of each column in total-relation matrix is equal to 1 by the normalization method, and then the inner dependence matrix can be acquired.

\subsection{Proposed methodology}

This section builds a structure for determining priorities of distribution centers location from strategic point of view based on various influential factors mentioned previously. The procedure of the proposed method is explained as follows:

Step 1: Identifying expert decision makers and forming a committee. We need to identify the people who have the knowledge about organizational processes so that we can properly plan the project and avoid wasting effort in gathering the required knowledge. For each particular topic, it is very useful to 
understand which expert can determine the relations among the influential factors of locating distribution centers in each balanced scorecard perspective. Also, it is necessary to form a committee comprising of selected experts from all departments, for determining the relations among balanced scorecard from strategic supply chain dimension.

Step 2: Determining relations. In this step steering committee in consolation with experts determines the relations among balanced scorecard perspectives and among influential factors in each perspective internally (initial direct-relation matrix $A$ ). The existing relation among balanced scorecard perspectives should be determined according to kind of organization activities and fields of action. In the other hand internal relations among each perspective criteria is affected by current situations and barriers in organization.

Step 3: Determining strategic priorities Once the relationships are determined, DEMATEL is implemented to measure the relative priorities of BSC perspectives and criteria for each perspective. Based on the initial direct-relation matrix $A$, the normalized direct-relation matrix $X$ is calculated through Eq. (1). Then, the total-relation matrix $T$ is calculated based on Eq. (3). A causal diagram is prepared through Eqs. (4-6). The causal diagram is built with the horizontal axis $(D+R)$ called "Prominence"' and the vertical axis $(D-R)$ called "Relation". The horizontal axis "Prominence" shows the relative importance of each factor, whereas the vertical axis, Relation, divides factors into cause and effect groups. Generally, when the $(D-R)$ is positive, the factor belongs to the cause group. Otherwise, the factor belongs to the effect group. Hence, causal diagrams can visualize the complicated causal relationships of factors into a visible structural model. We can also make proper decisions by recognizing the difference between cause and effect factors.

\section{Results}

An oil refining and distributing company would like to establish gas stations all over the country. A committee of expert decision makers is formed to determine the relative importance of all criteria. The aim is to select the proper region for location gas station. In this section, we implement the proposed model for this case study.

Step 1: At first, steering committee was formed comprising of the ten experts from all existing departments.

Step 2: In second step by means of who-where matrix which indicates among employees who can determine the relations among the influential factors in each balanced scorecard perspective, steering committee asked totally from 50 experienced employees to determine the relations among balanced scorecard perspectives and among influential factors for locating distribution centers in each perspective according to kind of organization activities (oil industry) and fields of action (refine and distribution) which is illustrated in Fig. 1.

Step 3: As described in step 3 in the proposed methodology, strategic priorities of BSC perspectives in locating distribution centers and influential factors for each perspective are determined by using DEMATEL method and total relationships matrices are demonstrated in Tables 2 to Table 6 .

\section{Table 2}

Total relationships matrices for BSC perspectives

\begin{tabular}{llllllll}
\hline & BSC1 & BSC2 & BSC3 & BSC4 & D & D+R & D-R \\
\hline BSC1 & 1.614458 & 1.518072 & 1.349398 & 1.349398 & 5.8313253 & 13.096386 & -1.43373 \\
BSC2 & 1.686747 & 1.108434 & 1.096386 & 1.096386 & 4.98795181 & 10.819277 & -0.84337 \\
BSC3 & 2.127175 & 1.686747 & 1.277108 & 1.499331 & 6.59036145 & 11.662651 & 1.518072 \\
BSC4 & 1.83668 & 1.518072 & 1.349398 & 1.127175 & 5.8313253 & 10.903614 & 0.759036 \\
R & 7.26506 & 5.831325 & 5.072289 & 5.072289 & & & \\
\hline
\end{tabular}




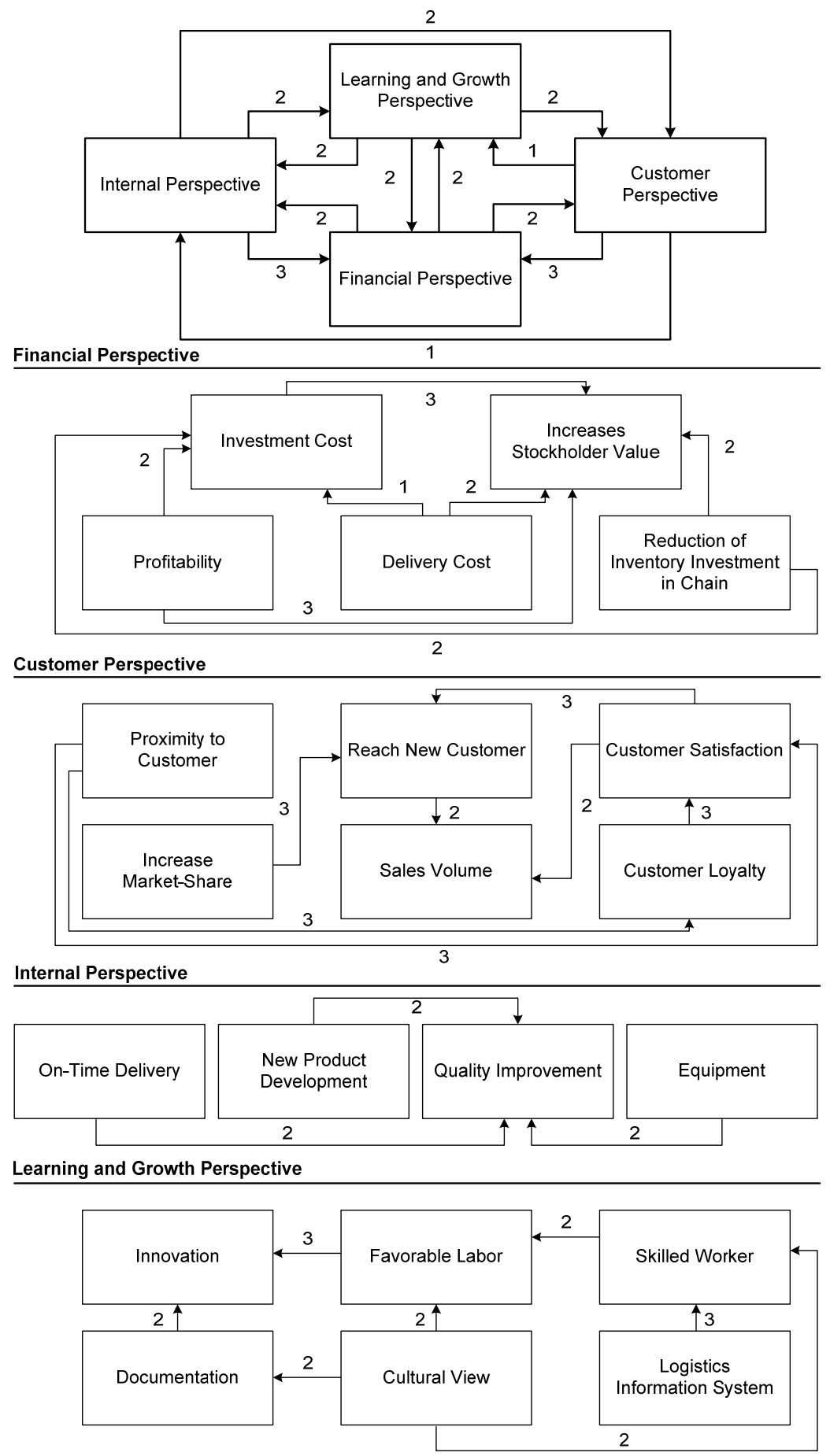

Fig. 1. The relationships among BSC perspectives and knowledge management benefits for each perspective

Table 3

Total relationships matrices for financial perspective

\begin{tabular}{lllllllll}
\hline & F1 & F2 & F3 & F4 & F5 & D & D+R & D-R \\
\hline F1 & 0 & 0.6 & 0 & 0 & 0 & 0.6 & 1.6 & -0.4 \\
F2 & 0 & 0 & 0 & 0 & 0 & 0 & 2.6 & -2.6 \\
F3 & 0.4 & 0.84 & 0 & 0 & 0 & 1.24 & 1.24 & 1.24 \\
F4 & 0.2 & 0.52 & 0 & 0 & 0 & 0.72 & 0.72 & 0.72 \\
F5 & 0.4 & 0.64 & 0 & 0 & 0 & 1.04 & 1.04 & 1.04 \\
R & 1 & 2.6 & 0 & 0 & 0 & & & \\
\hline
\end{tabular}


Table 4

Total relations matrixes for customer perspective

\begin{tabular}{llllllllll}
\hline & C1 & C2 & C3 & C4 & C5 & C6 & D & D+R & D-R \\
\hline C1 & 0 & 0.441176 & 0.75 & 0 & 0.397059 & 0.5 & 2.088235 & 2.088235 & 2.088235 \\
C2 & 0 & 0.058824 & 0 & 0 & 0.352941 & 0 & 0.411765 & 2.5 & -1.67647 \\
C3 & 0 & 0.588235 & 0 & 0 & 0.529412 & 0 & 1.117647 & 2.367647 & -0.13235 \\
C4 & 0 & 0.529412 & 0 & 0 & 0.176471 & 0 & 0.705882 & 0.705882 & 0.705882 \\
C5 & 0 & 0.176471 & 0 & 0 & 0.058824 & 0 & 0.235294 & 2.014706 & -1.54412 \\
C6 & 0 & 0.294118 & 0.5 & 0 & 0.264706 & 0 & 1.058824 & 1.558824 & 0.558824 \\
R & 0 & 2.088235 & 1.25 & 0 & 1.779412 & 0.5 & & & \\
\hline
\end{tabular}

Table 5

Total relations matrixes for internal perspective

\begin{tabular}{|c|c|c|c|c|c|c|c|}
\hline & I1 & I2 & I3 & I4 & D & $\mathbf{D}+\mathbf{R}$ & D-R \\
\hline I1 & 0 & 0 & 0.666667 & 0 & 0.66666667 & 0.6666667 & 0.666667 \\
\hline $\mathrm{I} 2$ & 0 & 0 & 0.333333 & 0 & 0.33333333 & 0.3333333 & 0.333333 \\
\hline I3 & 0 & 0 & 0 & 0 & 0 & 2 & -2 \\
\hline $\mathrm{I} 4$ & 0 & 0 & 1 & 0 & 1 & 1 & 1 \\
\hline $\mathrm{R}$ & 0 & 0 & 2 & 0 & & & \\
\hline
\end{tabular}

Table 6

Total relations matrixes for learning \& growth perspective

\begin{tabular}{llllllllll}
\hline & L1 & L2 & L3 & L4 & L5 & L6 & D & D+R & D-R \\
\hline L1 & 0 & 0 & 0 & 0 & 0 & 0 & 0 & 2.456 & -2.456 \\
L2 & 0.6 & 0 & 0 & 0 & 0 & 0 & 0.6 & 1.96 & -0.76 \\
L3 & 0.76 & 0.6 & 0 & 0 & 0 & 0 & 1.36 & 1.96 & 0.76 \\
L4 & 0.4 & 0 & 0 & 0 & 0 & 0 & 0.4 & 0.4 & 0.4 \\
L5 & 0.24 & 0.4 & 0 & 0 & 0 & 0 & 0.64 & 0.64 & 0.64 \\
L6 & 0.456 & 0.36 & 0.6 & 0 & 0 & 0 & 1.416 & 1.416 & 1.416 \\
R & 2.456 & 1.36 & 0.6 & 0 & 0 & 0 & & & \\
\hline
\end{tabular}

Fig. 2 shows the relationships among different BSC perspectives for locating distribution centers in supply chain based on the results of the implementation of the proposed model reported in Tables 2-6. The results are obtained by by mapping a dataset of $\left(D_{k}+R_{k}, D_{k}-R_{k}\right)$.

As illustrated in Fig. 2, the financial perspective represents the most important strategy for the implementation of the proposed model of this paper on our case study. Generally speaking, financial perspective plays an important role on many real-world problems. In addition, based on Fig. 2 the evaluation criteria were visually divided into the cause group, including "Learning and Growth" perspective and "Internal" perspective and the effect group, including "Customer" perspective and "Financial" perspective. Therefore, if the company wishes to reach a high level of performance in terms of the effect group strategies, it must first control and pay much attention to the cause group criteria.

Within the cause group, the strategy of "Internal" is the most important factor for locating distribution centers, whereas the "Internal" plays the effective role on the other strategies. In contrast, the "Financial" strategy is the most easily improved of the effect group strategies. 


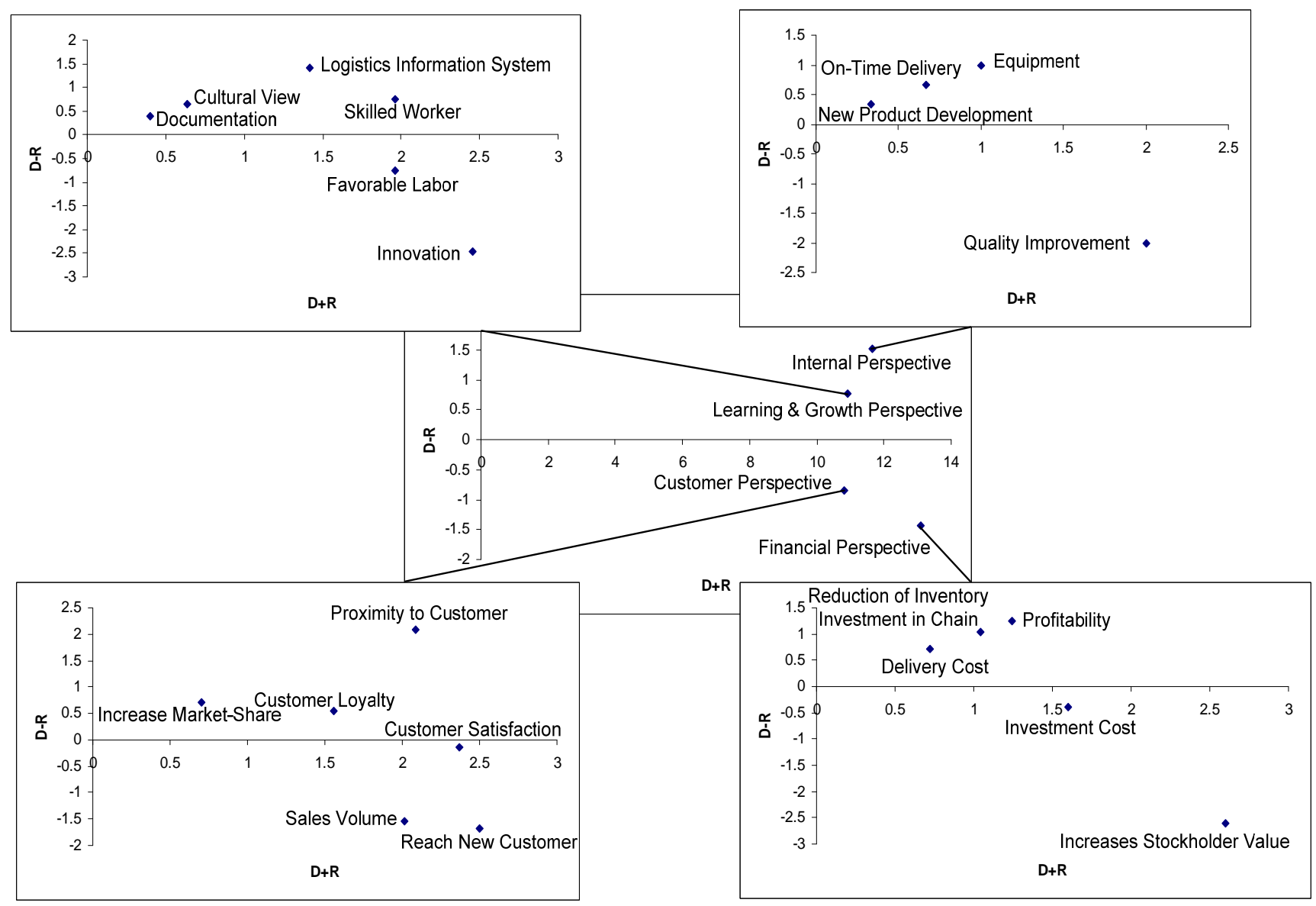

Fig. 2. The cause \& effect relationships among different BSC factors based on the implementation of the proposed model

\section{Conclusion}

Distribution center location in supply chain directly affects the process of satisfying need and demand for products. This paper proposed a comprehensive method to rank priorities of locating distribution centers in supply chain. The proposed model used a DEMATEL model to rank important issues affecting different BSC perspectives and the results were illustrated using some tables and figures. The implementation of our integrated BSC-DEMATEL was used for a real-world case study of oil industry and the results were analyzed. The proposed model of this paper could be used for other problems in supply chain such as supplier evaluation and problems. There are other multiple attribute decision-making methods such as TOPSIS and VIKOUR, which could be applied for ranking the alternatives and it would be interesting to compare the results with the outcome of the proposed model of this paper.

\section{References}

Brewer, P. C., \& Speh, T. W. (2000). Adapting the balanced scorecard to supply chain management. Supply Chain Management Review, 5(2), 48-56.

Bullinger, H.-J., Kühner, M., \& Van Hoof, A. (2002). Analyzing supply chain performance using a balanced measurement method. International Journal of Production Research, 40(15), 35333543.

Chan, C. K., \& Lee H. W. J. (2005). Successful Strategies in Supply Chain Management. Idea Group Inc.

Chopra, S., \& Meindl, P. (2003). Supply chain management: Strategy, planning and operation. Upper Saddle River, NJ: Pearson Prentice Hall. 
Chorafas, D. N. (2001). Integrating ERP, CRM, Supply Chain Management, and Smart Materials, CRC Press LLC Auerbach.

Chou, S., Chang Y., \& Shen C. (2008). A fuzzy simple additive weighting system under group decision-making for facility location selection with objective/subjective attributes. European Journal of Operational Research, 189, 132-145.

Chu T.-C. (2002). Selecting plant location via a fuzzy TOPSIS approach. International Journal of Advanced Manufacturing Technology, 20, 859-864.

Chu T.-C., \& Lai M.-T. (2005). Selecting distribution centre location using an improved fuzzy MCDM approach. International Journal of Advanced Manufacturing Technology, 26, 293-299.

Delffmann, W. (2000). Supply chain management in the global context. Working Paper No. 102, Department of General Management, Business Planning and Logistics, The University of Cologne.

Ertugrul I., \& Karakasoglu N. (2008). Comparison of fuzzy AHP and fuzzy TOPSIS methods for facility location selection. International Journal of Advanced Manufacturing Technology, 39 (7-8), 783-795.

Fontela, E., \& Gabus, A. (1976). The DEMATEL observer, DEMATEL 1976 Report. Switzerland Geneva: Battelle Geneva Research Center.

Frazelle E., (2002). Supply Chain Strategy: The Logistics of Supply Chain Management, The McGraw-Hill Companies Inc.

Gabus, A., \& Fontela, E. (1972). World problems, an invitation to further thought within the framework of DEMATEL. Switzerland, Geneva: Battelle Geneva Research Centre.

Gabus, A., \& Fontela, E. (1973). Perceptions of the world problematique: Communication procedure, communicating with those bearing collective responsibility (DEMATEL report no. 1). Switzerland Geneva: Battelle Geneva Research Centre.

George, J. F., Dennis, A. R., \& Nunamaker, J. F. (1992). An experimental investigation of facilitation in an EMS decision room. Group Decision and Negotiation, 1, 57-70.

Hackman, J. R., \& Kaplan, R. E. (1974). Interventions into group process: An approach to improving the effectiveness of groups. Decision Sciences, 5, 459-480.

Hori, S., \& Shimizu, Y. (1999). Designing methods of human interface for supervisory control systems. Control Engineering Practice, 7(11), 1413-1419.

Kahraman C., Ruan D., \& Dogan I. (2003). Fuzzy group decision-making for facility location selection. Information Sciences, 157, 135-153.

Kamaike, M. (2001). Design elements in the passenger car development: The classification and the influence analysis in case of recreational vehicle. Japanese Society for the Science of Design, 48(1), 29-38.

Kanji, G. K. \& Wong, A. (1999). Business Excellence model for supply chain management. Total Quality Management, 10(8), 1147- 1168.

Kaplan, R. \& Norton, D. (1993). Putting the balanced scorecard to work. Harvard business review,71(5), 134-142.

Kaplan, S. \& Norton, D. (1996). The Balance Scorecard. Translating Strategy into Action, Harvard Business School Press, Cambridge, MA.

Kaplan, S., \& Norton, D. (2000). Having Trouble with your Strategy? Then Map It. Harvard Business Review, 78 (5), 167-176.

Kaplan, R. \& Norton, D. (2004). Strategy Maps: Converting Intangible Assets to Tangible Outcomes, Harvard Business School Press.

Karathanos, D., \& Karathanos, P. (2005). Applying the Balanced Scorecard to Education. Journal of Education for Business, 80 (4), 222-230.

Kuo M. S., Liang G. S., \& Huang W. C. (2006). Extensions of the multicriteria analysis with pairwise comparison under a fuzzy environment. International Journal of Approximate Reasoning 43, 268285.

Metters, R. (1997). Quantifying the bullwhip effect in supply chains. Journal of Operations Management, 15, 89-100. 
Nair, M. (2004). Essentials of Balanced Scorecard. John Wiley \& Sons.

Schechter, D. \& Sander, G. (2002). Delivering The Goods: The Art of Managing Your Supply Chain, John Wiley \& Sons, Inc., Hoboken, New Jersey.

Smith, M. (2005). The Balance scorecard. Financial Management, 27-28.

Smock, D. (2003). Supply chain management: What is it? Purchasing, 132(13), 45-49.

Stadtler H., \& Kilger C. (2005). Supply Chain management and Advanced Planning: Concepts, Models, Software and Case studies. Springer, Berlin, Germany.

Tsai, W.-H., \& Chou, W.-C. (2009). Selecting management systems for sustainable development in SMEs: A novel hybrid model based on DEMATEL, ANP, and ZOGP. Expert Systems with Applications, 36(2), 1444-1458.

Tzeng, G.-H., Chiang, C.-H., \& Li, C.-W. (2007). Evaluating intertwined effects in e-learning programs: A novel hybrid MCDM model based on factor analysis and DEMATEL. Expert Systems with Applications, 32, 1028-1044.

Waters, D. (2007). Global logistics: new directions in supply chain management. Kogan Page publishing, London, United Kingdom.

Wu, W.-W., \& Lee, Y.-T. (2007). Developing global managers' competencies using the fuzzy DEMATEL method. Expert Systems with Applications, 32, 499-507.

Wu, W.-W. (2008). Choosing knowledge management strategies by using a combined ANP and DEMATEL approach. Expert Systems with Applications, 35, 828-835.

Yamazaki, M., Ishibe, K., Yamashita, S., Miyamoto, I., Kurihara, M., \& Shindo, H. (1997). An analysis of obstructive factors to welfare service using DEMATEL method. Reports of the Faculty of Engineering, Yamanashi University, 48(1), 25-30.

Yong D. (2006). Plant location selection based on fuzzy TOPSIS. International Journal of Advanced Manufacturing Technology, 28, 839-844.

Yuzawa, A. (2002). A state and subjects of TMO conception for city core vitalization countermeasure: A case study of Maebashi TMO Conception. Bulletin of Maebashi Institute of Technology, 5(1), 61-67.

Zandin, K. B., \& Maynard, H. B. (2001). Maynard's Industrial Engineering Handbook, McGraw-Hill 